\title{
What do parents know about vitamins?
}

\author{
M L B Ko, N Ramsell, J A Wilson
}

\begin{abstract}
Parents of 120 children attending child health clinics answered a questionnaire on their understanding of vitamins. Fifty four children $(45 \%)$ were taking vitamins; $12(22 \%)$ were given the wrong dose. Only 19 parents (35\%) knew when to stop supplements and $25(46 \%)$ did not realise overdosage was potentially harmful. Only six children (11\%) were receiving professional supervision. This indicates a need to improve parental understanding and professional supervision.
\end{abstract}

\section{(Arch Dis Child 1992;67:1080-1)}

Vitamin supplementation to children has been a longstanding practice. In particular, since the reported increased incidence of rickets in Asian children in the late 1970s, people are more aware of the need of supplementation. ${ }^{1}$ The Department of Health and Social Security stated in 1988 that 'at present it remains prudent to safeguard infants by giving supplementary vitamins' and recommended that 'vitamins should be given to infants and children from age 6 months up to at least 2 years and preferably 5 years.' Parents are able to obtain their supply of vitamins from child health clinics under the Welfare Food Scheme. ${ }^{2}$ However, there are also many alternative preparations available to parents from other sources, including chemists and health food shops, without a prescription. Therefore it is difficult to supervise the administration of vitamins to children by their parents.

Little is known about the general public's understanding of the use and purpose of vitamins. The majority probably do not treat them as a form of medication and are unaware of the potential harm of inappropriate administration. ${ }^{3}$ Prompted by a recent case of gross hypercalcaemia due to chronic vitamin $\mathrm{D}$ overdosage in which the parents had not obtained their vitamins via a medical source and had not received supervision, ${ }^{4}$ we carried out this study to find out parental understanding of vitamin

Table 1 Number of children on vitamins and their age distribution

\begin{tabular}{llll}
\hline Age & $\begin{array}{l}\text { No of } \\
\text { children }\end{array}$ & $\begin{array}{l}\text { No on } \\
\text { vitamins }\end{array}$ & $\begin{array}{l}\text { No not } \\
\text { given vitamins }\end{array}$ \\
\hline $\begin{array}{l}\text { Birth-4 months } \\
\text { 4 months-1 year }\end{array}$ & 35 & 12 & 23 \\
1-2 years & 37 & 16 & 21 \\
2-5 years & 22 & 16 & 6 \\
Total & 26 & 10 & 16 \\
$\begin{array}{l}\text { Children on both fortified milk and vitamins } \\
\text { Children under 2 years who received no vitamin }\end{array}$ & 54 & 66 \\
supplements from any source & 120 & $15(13 \%)$ & \\
\hline
\end{tabular}

supplementation and the degree of supervision received among our local population.

\section{Subjects and methods}

Parents of 120 children aged between 6 weeks and 5 years, who attended five of our local child health clinics, were interviewed by two doctors using a structured questionnaire. The parents were chosen at random and the distribution of their ethnic origins (59\% white, $32 \%$ Asian, $6 \%$ Afro-Caribbean, 3\% others) suggests that they were a fair representation of the local population (UK and Irish 70.2\%, New Commonwealth and Pakistan $24 \cdot 1 \%$, and rest of the world $5 \cdot 7 \%$; Census 1981, Harrow area statistics). They were asked questions to determine:

(a) If their children were given vitamins,

(b) If vitamins were given appropriately according to the DHSS guidelines, ${ }^{2}$

(c) If they understood the use and purpose of vitamins,

(d) If they were aware of the potential dangers of overdosage, and

(e) If they had been receiving professional advice and supervision.

The questionnaire was designed so as to minimise subjective evaluation.

\section{Results}

Tables 1 and 2 show the results obtained. There were 54 children on vitamins (45\%); 15 of these children were already on fortified infant formula milk which contains adequate amounts of vitamin supplements and therefore some may feel they were on vitamins unnecessarily. Their parents were advised to stop supplements until they were weaned on to cows' milk. There were 15 children aged under 2 years who did not receive any form of supplementation and some of them were advised to start supplements according to the DHSS guidelines. ${ }^{2}$ Of the 54 children on vitamins, 16 parents obtained their vitamins privately (30\%), 34 were advised to start on vitamins by a health professional $(63 \%)$, usually the health visitor ( 33 out of 34 ). Only six continued to receive professional supervision

Table 2 Information from the parents of children receiving vitamins $(n=54)$; results are number $(\%)$

\begin{tabular}{lr}
\hline Able to name vitamin preparation correctly & $24(44)$ \\
Able to define correct dosage to be given & $42(78)$ \\
Aware of when to cease supplementation & $19(35)$ \\
Advised to commence vitamins by professionals & $34(63)$ \\
Currently receiving advice from professionals & $6(11)$ \\
Vitamins obtained from sources other than & $16(30)$ \\
child health clinics & $25(46)$ \\
Unaware of dangers of overdosage &
\end{tabular}


(11\%) and only 19 knew when to cease supplementation (35\%).

Twelve children were given the wrong dose (22\%), but fortunately all had been given a smaller dose than recommended. Parents of 25 children who were on vitamins did not realise that overdosage was potentially dangerous $(46 \%)$, and all of their children were receiving preparations that contain vitamins $A$ and $D$, where harmful overdosage has been well documented.

\section{Discussion}

The results of this study show that a large number of parents do not have sufficient knowledge of vitamins to be able to administer supplementation to their children correctly and safely. The population studied is biased towards parents who may be better informed than the general public, as they attend child health clinics and therefore have many contacts with health professionals. The majority of parents interviewed received professional advice, usually from the health visitor, before their children started on vitamin supplements; thereafter, most of them stopped seeking professional advice but continued with the supplements. This may partly be due to decreased contacts with health visitors with the increasing age of their children. This may also explain why so few of them have any ideas how long to continue supplements. Some parents do not realise that they can obtain vitamins relatively cheaply from child health clinics and pay more for similar preparations elsewhere. The most disturbing result is that almost half of the parents were not aware of the dangerous overdosage.

It also appears that health professionals are not very effective in advising parents about vitamins. General practitioners, health visitors, clinical medical officers, and other paediatricians should use their parental contacts, especially during child health surveillance, as opportunities to discuss the use of vitamins. Establishing a unified local policy on feeding and vitamin supplementation would be helpful for professionals and would avoid confusion and contradictory advice. Written or printed advice would help to reinforce the points discussed. There is very useful information on dosage and recommended duration of vitamin supplementation and also warning of overdosage in the booklet Birth to Five Years published by the Health Education Authority, which is available to all first time mothers. ${ }^{5}$ It is also useful to point out that the information in the national model of parent held child health records seems inadequate as it merely states 'ask your health visitor about the need for extra vitamins and fluoride' (Castlemead Publications, 1990).

The results of this study suggest that more effort should be made to educate the general public on the use of vitamin supplementation. With the recent surge of interest in supplementing children to improve their cognitive functions, ${ }^{6}$ it is especially important to make the public aware of potentially harmful effects of inappropriate administration of vitamins. Health professionals should also aim, and be reminded, to improve supervision.

1 Anonymous. Rickets in Asian children [Editorial]. $B M \mathcal{F}$ 1979;i:1744.

2 Department of Health and Social Security. Present day practice in infant feeding: third report. London: HMSO practice in infant

3 Evans CDH, Lacey JH. Toxicity of vitamins: complications of a health movement. $B M \mathcal{Y}$ 1986;292:509-10

4 Ko MLB, Liberman MM, Salzman M. Chronic vitamin D overdosage: a reminder. Arch Dis Child 1991;66:1002.

5 Health Education Authority. Birth to five years: a guide to the first five years of being a parent. London: HMSO, 1991:10-1.

6 Schoenthaler SJ, Amos SP, Eysenck HJ, Peritz E, Yudkin J. Controlled trial of vitamin-mineral supplementation effects on intelligence and performance. Person Individ Diff 1991;12:351-62. 